scope of natural selection, that they are non-utilitarian and not correlated with any useful characters. This difficulty would appear to be obviated in the illustration which is now given.

It is noteworthy that many eminent men were begotten by fathers of ripe age : the father of Francis Bacon was fifty-two years of age, of John Herschel fifty-four, of Robert Boyle sixty-one, of William Pitt fifty-one, of Samuel Johnson fifty-three, of John Hunter sixty-five and of Charles Parsons fifty-four. This suggests that capability may be in some degree an acquired character, and that the older the father the greater the chance of it being acquired.

An attempt has been made to determine whether

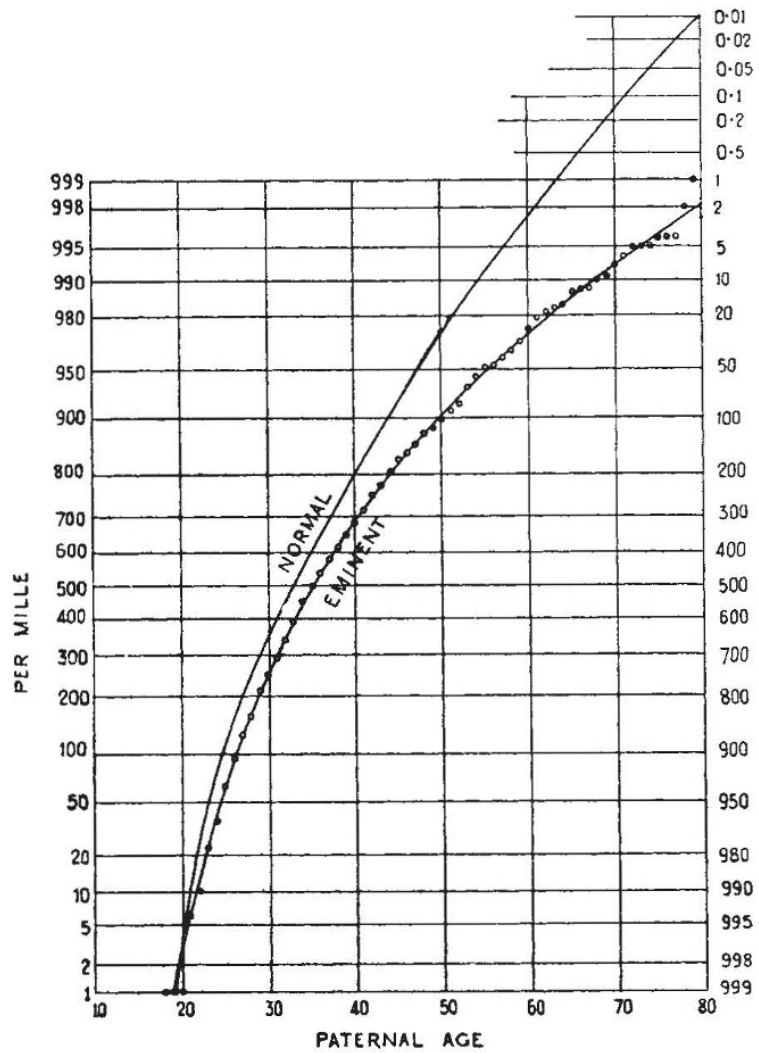

Fig. 1.

this can be substantiated. In the "Encyclopædia Britannica" (Fourteenth Edition) one thousand persons are noticed (exclusive of those mentioned on account of inherited titles) for whom the date of the father's birth is given. These are considered to be of outstanding capability and the paternal age has been compared with that for a more normal population.

The comparison has been made by plotting upon permille paper ${ }^{1}$ the frequency distribution of the paternal age both for the eminent thousand and also for one hundred thousand children under one year recorded in the census of Scotland for 1921 (see Fig. 1).

This simple investigation appears to show that capability is an inheritable character acquired by those of mature years. The difference between the two curves in the figure is so striking - the proportion with paternal age more than forty-five years is twice, more than sixty years ten times, and more than seventy years fifty times the normal - that it is thought well to publish the facts without proceeding to examine other statistics.

No. 3283 , VoL. 130]
In compiling the data, it was observed that the grandfathers of many eminent men were of ripe age ; Ruskin's father, who was only thirty-five years of age, was born when his father was fifty-three years of age. A. F. Dufton.

Greenbank, Garston, Hertfordshire, Sept. 1.

1 Phil. Mag., 10, 556; 1930 ; and 11, 454; 1931.

Observations on Filmed and Filtered Vowels

REFERRING to Mr. W. E. Benton's letter on vowel sounds, ${ }^{1}$ there is a further point to which attention may be directed, namely, the effect of the changes of attitude or 'expression" of the larynx and adjoining parts which accompany vowel formation.

At the International Phonetic Congress at Amsterdam, last July, Dr. Oscar Russell demonstrated the action of his own larynx while articulating various vowel sounds. It was evident that the laryngeal region is very active, and shows a different attitude at each change of vowel.

On the other hand, as Mr. Benton points out, the behaviour of my models showed that recognisable vowel sounds are produced by passing the vibrations of a reed through a pair of suitably tuned resonators in series. It also showed that a complete range of voiced vowel sounds could be produced, over a considerable musical range in each case, by simply altering the effective length of the vibrating reed.

The elaborate adjustments of the laryngeal region are evidently not essential to vowel production; they probably assist by providing in each case a funda. mental vibration having overtones in the regions of frequency characteristic of the vowel in question.

Dr. Russell also articulated-in a whisper-some of the so-called voiced and unvoiced consonants (B, P ; V, F), and it was apparent that, in this case also, the laryngeal region takes an active part in differentiating the "voiced' from the 'unvoiced' sound, when both are whispered. This, incidentally, confirms the conclusion which I had drawn ${ }^{2}$ from the behaviour of models.

The exact nature of the human adjustments requires investigation.

At my request, Dr. Russell also varied his facial expression while I watched his larynx. It was seen that at each change of facial expression-from a smile to a scowl, for example - there was also a change of expression in the laryngeal region.

This correlation-which also needs detailed investigation-offers a simple explanation of the emotional language of phonation, and completes the gestural picture of human speech.

The mouth gestures of articulation correlate with pantomimic hand or bodily gesture, and the changing attitudes of the laryngeal region correlate with changes of facial expression.

1 Devonshire Terrace, London, W.2, Sept. 13.

NATURE, Sept. 24, p. 475.

Proc. Roy. Soc., A, 114, 98; 1927.

\section{Electron Oscillations}

LAST year I made a series of observations on shortwave oscillations in three-electrode valves with positive grid. Details of the experiments will be published elsewhere, but a brief account here, in relation to a theory on the mechanism of these oscillations, as electron oscillations, which I have worked out recently, may prove interesting. ${ }^{1}$

The experimental arrangement was similar to that used by most workers, ${ }^{2}$ differing only in a few details. 